\title{
AS FORMAS DE VIOLÊNCIA À MULHER SOB A PROTEÇÃO DA LEI N 11.340/06 (LEI MARIA DA PENHA)
}

Tainara Andrea de Souza

Universidade do Oeste Paulista - UNOESTE, curso de Direito, Presidente Prudente, SP. E-mail Tainara_a_@hotmail.com

\section{RESUMO}

O presente artigo busca apresentar e compreender, à luz da Lei 11.340/06, esta conhecida como lei Maria da Penha, veremos em seu artigo $7^{\circ}$, os tipos de violência doméstica contra a mulher, elencada nos seus incisos, bem como as considerações gerais sobre tais tipos de violências. 0 método utilizado foi o dedutivo legal, aplicando-se a interpretação da legislação e doutrina. Conclui-se que o principal objetivo deste artigo é demostrar quais são as formas de violência doméstica e familiar contra a mulher, que são violência física, psicológica, sexual, patrimonial e moral.

Palavras-chave: Violência doméstica. Direitos da Mulher. Lei n¹1.340/06.

THE FORMS OF VIOLENCE OF WOMEN UNDER THE PROTECTION OF LAW N ${ }^{\bullet} 11.340$ / 06 (LAW MARIA DA PENHA)

\begin{abstract}
This article seeks to present and understand, in light of Law 11.340 / 06, this known as the Maria da Penha law, we will see in article seventh, the types of domestic violence against women, listed in its paragraphs, as well as the general considerations about such types of violence. The method used was the legal deductive, applying the interpretation of the legislation and doctrine. It is concluded that the main objective of this article is to demonstrate the forms of domestic and family violence against women, which are physical, psychological, sexual, property and moral violence.
\end{abstract}

Keywords: Domestic violence. Women rights. Law No. 11,340 / 06. 


\section{INTRODUÇÃO}

O presente artigo, apresenta a importância da Lei 11.340, conhecida como Lei Maria da Penha, que busca prevenir a violência de gênero no âmbito doméstico ou familiar, que é qualquer tipo de agressão contra a mulher, buscando junto a constituição federal de 1988 em seu artigo $226, \S 8^{\circ}$ todas as formas possíveis para coibir e prevenir, com a tentativa de eliminar essa violência, em busca da proteção das mulheres.(BIANCHINI, 2016).

Infelizmente ainda há mulheres que são agredidas por seus parceiros, estes acham que são donos, que detém o poder sob suas companheiras e acham que porque sustentam a casa tem autoridade e poder de decidir a vida de suas filhas e esposas.

O presente trabalho busca apresentar e compreender, à luz da Lei 11.340/06, (lei maria da penha), quais são as formas de violência existentes contra à mulher.

\section{METODOLOGIA}

O presente estudo será desenvolvido por meio de pesquisa bibliográfica em doutrinas, artigos eletrônicos, legislação, cujo método de análise apoia se em discussão partindo do raciocínio lógico do geral para o particular, ou seja, o dedutivo.

\section{TIPOS DE VIOLÊNCIA}

\section{VIOLÊNCIA FÍSICA}

A abordagem da violência física está inserida no Art. $7^{\circ}$, I da Lei 11.340/06 quando dispõe que "a violência física, entendida como qualquer conduta que ofenda sua integridade ou saúde corporal".

O conceito de violência física trata do uso da força, mediante socos, tapas, pontapés, empurrões, arremesso de objetos, queimaduras, etc., sendo também utilizado agentes cortantes, em vários casos de violência física perpetrados contra a mulher, visando, desse modo, ofender a integridade ou a saúde corporal da vítima, deixando ou não marcas aparentes, naquilo que se denomina tradicionalmente, "vis corporalis", expressão que define a violência física, (BIANCHINI, 2016).

A integridade física e a saúde corporal são protegidas juridicamente pela lei penal (CP, art. 129 lei 2.848/40). A violência doméstica já configurava forma qualificada de lesões corporais, foi inserida no Código Penal em 2004, com o acréscimo do $\S 9^{\circ}$ ao artigo 129 do CP. A Lei Maria da Penha limitou-se a alterar a pena desse delito: de 6 meses a um ano, a pena passou para de 3 meses a 3 anos.

Embora não tenha havido mudança na descrição do tipo penal, ocorreu a ampliação do seu âmbito de abrangência. Como foi dilatado o conceito de família, albergando também as unidades domésticas e as relações de afeto, a expressão "relações domésticas" constante do tipo penal passa a ter uma nova leitura.

Não só a lesão dolosa, também a lesão culposa constitui violência física, pois nenhuma distinção é feita pela lei sobre a intenção do agressor.

\section{VIOLÊNCIA PSICOLÓGICA}

No que diz respeito a violência psicológica o Art. $7^{\circ}$, II da Lei dispõe que:

A violência psicológica, entendida como qualquer conduta que lhe cause dano emocional e diminuição da autoestima ou que lhe prejudique e perturbe o pleno desenvolvimento ou que vise degradar ou controlar suas ações, comportamentos, crenças e decisões, mediante ameaça, constrangimento, humilhação, manipulação, isolamento, vigilância constante, perseguição contumaz, insulto, chantagem, ridicularização, exploração e limitação do direito de ir e vir ou qualquer outro meio que lhe cause prejuízo à saúde psicológica e à autodeterminação. 
Conforme se constata a violência psicológica é a agressão emocional. Ocorre quando o agente inferioriza, ameaça, humilha, manipula, discrimina a vítima é, assim, a denominada "vis compulsiva".

Trata-se de previsão que não estava contida na legislação pátria, mas a violência psicológica foi incorporada ao conceito de violência contra a mulher na Convenção Interamericana para Prevenir, Punir e Erradicar a Violência Doméstica, conhecida como Convenção de Belém do Pará. Trata da proteção da autoestima e da tal violência encontra forte alicerce nas relações desiguais de poder entre os sexos.

Assim veremos que é a mais frequente e talvez seja a menos denunciada. Essa é a forma de violência pode manifestar-se de modo sutil, e a vítima muitas vezes nem se dá conta, das atitudes como "orientar" quanto o modo de falar, as roupas que deve vestir, quais os amigos que podem ou não conversar, ou seja, atitudes que evoluem gradativamente para um controle da vida da vítima, passando para agressões verbais, silêncios prolongados, tensões, manipulações de atos e desejos, que são violência e devem ser denunciados.(FERNANDES, 2015)

\section{VIOLÊNCIA SEXUAL}

A violência sexual da mesma forma é trazida pela legislação em seu Art. 7으, III da seguinte forma:

A violência sexual, entendida como qualquer conduta que a constranja a presenciar, a manter ou a participar de relação sexual não desejada, mediante intimidação, ameaça, coação ou uso da força; que a induza a comercializar ou a utilizar, de qualquer modo, a sua sexualidade, que a impeça de usar qualquer método contraceptivo ou que a force ao matrimônio, à gravidez, ao aborto ou à prostituição, mediante coação, chantagem, suborno ou manipulação; ou que limite ou anule o exercício de seus direitos sexuais e reprodutivos.

A Convenção Interamericana para Prevenir, Punir e Erradicar a Violência Doméstica é chamada Convenção de Belém do Pará que reconheceu a violência sexual, contra a mulher, qualquer conduta, de ação ou omissão, baseada no gênero, que cause morte, dano ou sofrimento físico, sexual ou psicológico à qualquer mulher, tanto no âmbito público ou privado. (JESUS 2015)

O Código Penal é mais severo com relação aos crimes perpetrados com o abuso da autoridade decorrente de relações domésticas. Porém a Lei Maria da Penha ampliou o rol do artigo 61, II, "f" do código penal (lei $\mathrm{n}^{\circ}$ 2.848/1040 que ficou assim redigido: "Com abuso de autoridade ou prevalecendo-se de relações domésticas, de coabitação ou de hospitalidade, ou com violência contra a mulher na forma da lei específica").

Os crimes contra a liberdade sexual configuram violência sexual quando envolve os seguintes aspectos: prática de ato sexual contra a vontade da vítima ou contra a vítima sem discernimento de consentir, quando a vítima é obrigada a pendenciar o ato sexual, exploração da sexualidade da mulher, estupro, restrições dos direitos sexuais e reprodutivos ou que acarrete consequências à saúde da mulher. (FERNANDES, 2015)

\section{VIOLÊNCIA PATRIMONIAL}

A Lei Maria da Penha reconhece como violência patrimonial o ato de "subtrair" objetos da mulher, o que nada mais é do que furtar; o ato de "apropriar" e "destruir". Citado no inciso IV, da Lei 11.340/06, dispõe que:

Art. $7^{\circ}$, IV da Lei: "violência patrimonial, entendida como qualquer conduta que configure retenção, subtração, destruição parcial ou total de seus objetos, instrumentos de trabalho, documentos pessoais, bens, valores e direitos ou recursos econômicos, incluindo os destinados a satisfazer suas necessidades". 
Sendo assim são atos praticados contra a mulher, e que não é necessário a configuração da agressão contra a mulher, pois basta ter algum dos direitos mencionados acima violados. Lembrando que dentro de um contexto de ordem familiar, o crime não desaparece e nem fica sujeito à representação, podendo até ocorrer agravamento da pena caso o crime seja contra mulher com quem o agente mantém vínculo familiar ou afetivo. (FERNANDES, 2015)

\section{VIOLÊNCIA MORAL}

A violência moral encontra proteção penal nos delitos contra a honra: calúnia, difamação e injúria e é tratado em seu art. 7으, inciso V:"a violência moral, entendida como qualquer conduta que configure calúnia, difamação ou injúria".

A calúnia ocorre quando o agente imputa à vítima a prática de determinado fato criminoso sabidamente falso; difamação quando imputa à vítima a prática de determinado fato desonroso e injúria quando se atribui à vítima qualidades negativas. Normalmente se dá concomitante à violência psicológica.

\section{CONCLUSÃO}

Portanto esse artigo visa trazer comentários aprofundados das formas de violências existentes, demostrando as particularidades e características de cada uma e as influencias das mesmas no convívio da sociedade, que na maioria das vezes despercebido e acaba não sendo considerado como um tipo de violência.

Sendo assim conclui-se desta maneira que é necessária uma observação mais aprofundada e uma abordagem mais clara para identificar cada tipo de violência sofrido pelas mulheres, pretendendo assim com esse trabalho a identificar cada forma de violência e encontrar soluções para cada uma, para obter assim um número maior de denúncias, para prevenir, punir e erradicar a violência doméstica.

\section{REFERÊNCIA}

BRASIL, Decreto $n^{\circ}$ 1.973/1996. Convenção interamericana para prevenir, punir e erradicar a violência contra a mulher.

BRASIL, Decreto, lei n².848/1040, Código Penal.

BRASIL, Decreto, lei n 11.340/2006, Lei Maria da Penha.

BIANCHINI, Alice. Lei maria da penha: Lei n. 11.340/2006: aspectos assistenciais, protetivos e criminais da violência de gênero, 3. ed., São Paulo: Saraiva, 2016.

FERNANDES, Valeria Diez Scarance, Lei Maria da Penha: o processo penal no caminho da efetividade: abordagem jurídica e multidisciplinar, São Paulo: Atlas, 2015.

JESUS, Damásio de Violência contra a mulher: aspectos criminais da Lei n.11.340/2006, 2. ed., São Paulo: Saraiva, 2015. 